\title{
Benin Goitre in the General Surgery Department at Teaching Hospital Gabriel Touré
}

\author{
Madiassa Konate*, Amadou Traore, Moussa Samake, Abdoulaye Diarra, Boubacar Karembé, \\ Amadou Bah, Boubacar Yoro Sidibé, Kadiatou Doumbia, Tany Koné, Amadou Maiga, \\ Zakari Saye, Arouna Doumbia, Ibrahim Diakite, Bakary T. Dembelé, Alhassane Traore, \\ Lassana Kante, Adegné Togo
}

General Surgery at Teaching of Gabriel Toure, Bamako, Mali

Email: ^Konate8@gmail.com

How to cite this paper: Konate, M., Traore, A., Samake, M., Diarra, A., Karembé, B., Bah, A., Sidibé, B.Y., Doumbia, K., Koné, T., Maiga, A., Saye, Z., Doumbia, A., Diakite, I., Dembelé, B.T., Traore, A., Kante, L. and Togo, A. (2022) Benin Goitre in the General Surgery Department at Teaching Hospital Gabriel Touré. Surgical Science, 13, 15-22. https://doi.org/10.4236/ss.2022.131003

Received: November 9, 2021

Accepted: January 7, 2022

Published: January 10, 2022

Copyright $\odot 2022$ by author(s) and Scientific Research Publishing Inc. This work is licensed under the Creative Commons Attribution International License (CC BY 4.0).

http://creativecommons.org/licenses/by/4.0/

\section{(c) (i) Open Access}

\begin{abstract}
Introduction: Goitre is an increase in the volume of the thyroid gland. Goiters may be congenital or acquired, diffuse or nodular, functional or non-functional, benign or malignant. Purpose: The objectives of this work were to study and determine the frequency of benign goitre in the general surgery department of CHU Gabriel Touré, and to study epidemiological, clinical and therapeutic aspects. Patients and Method: This was a retrospective and prospective study conducted in the general surgery department of CHU Gabriel Touré, from January 1999 to December 2019. Included in the study were all patients with benign goiter confirmed in histology, hospitalized and treated in the service. Patients with thyroid malignant tumours, strumite, thyroid tract cyst, cervical abscess and neck trauma were not retained. Socio-demographic, clinical, para-clinical, therapeutic and post-operative aspects were the study parameters. Word processing and tables were done with Microsoft Word and Excel 2016 software. Data analysis was performed with Epi info7 software, the statistical test used was the Khi2 test and a value of $\mathrm{P}<$ 0.05 was considered statistically significant. Results: A total of 253 patient files were collected. Thyroidectomy represented 5.02\% (253/5036) of surgical procedures. The average age was 42.5 years with a standard deviation of 15.6 and extremes of 13.9 and 76 years. The sex ratio was 8.7 in favour of the female sex. Anterior cervical swelling was the most common reason for consultation with $90.0 \%$ (230/253). There were 118/253 cases of euthyroid goiter (46.6\%), 132/253 cases of hyperthyroid goiter $(52.2 \%)$ and $3 / 253$ cases of Basedow's disease (1.2\%). Histology revealed (178/253) cases of micro and macro follicular colloid adenoma (70.3\%), (27/253) cases of micro and macro follicular vesicular adenoma (10.7\%) and (48/253) cases of micro and macro vesicular hyperplasia. The most performed surgical techniques were subtotal
\end{abstract}


thyroidectomy with a rate of $138 / 253(54.5 \%)$ isthmo-lobectomy with a rate of $102 / 253(40.3 \%)$, lobectomy with a rate of $11 / 253(4.3 \%)$ and isthmectomy $1 / 253(0.4 \%)$. One-month follow-up was marked by 4 cases of surgical site infection (1.6\%), 2 cases of transient hypocalcemia (0.8\%). One-year follow-up was simple in $98.4 \%$ of cases, we noted 4 cases of keloid. The average length of hospitalization was $3.31 \pm 0.1$ days. Conclusion: Goiter surgery is relatively common in the general surgery department of CHU Gabriel Touré. Good preparation and better post-operative monitoring could help minimize post-operative complications.

\section{Keywords}

Benign Goitre, Epidemiological, Clinical and Therapeutic Aspects

\section{Introduction}

Goitre is an increase in the volume of the thyroid gland [1]. Goiters may be congenital or acquired, diffuse or nodular, functional or non-functional, benign or malignant [2]. The vulnerable population is represented by growing children, girls (during puberty) and young women (at reproductive age). The sex ratio is 4 girls/1 boy [3] [4]. The prevalence of goiter is related to the severity of iodine deficiency, according to the World Health Organization (WHO), the global frequency of goiter was estimated at about $15.8 \%$ in 2003 spread across the globe [5] of which: 6\% in North America [6]; 7\% in Switzerland [7]; 6.8\% in Sri Lanka [8]; $28.3 \%$ in Africa [9]. Prevention of goiter consists essentially of providing additional iodine to populations in endemic areas.

Treatment of goitre depends on symptomatology, volume and patient preference [9].

The last study done on the pathology of benign goitre in the general surgery department of CHU Gabriel Touré would date back to twenty years, so we initiated this study with the aim of studying the clinical aspects, epidemiological and therapeutic of benign goiter in the general surgery department at CHU Gabriel Touré.

\section{Objectives}

1) Overall Objective:

Study benign goitre in the general surgery department of C H U Gabriel Touré.

2) Specific Objectives:

Determine the frequency of benign goitre in the general surgery department of CHU Gabriel Touré; Describe epidemiological; clinical; clinical and therapeutic aspects of goiter.

\section{Methodology}

1) Study Framework 
This study was carried out in the Department of General Surgery at CHU Gabriel Touré.

2) Patients and Method

3) Type of study: This was a cross-sectional, retrospective and prospective study

4) Study period

This work spanned two phases: a retrospective phase running from January 1, 1999 to December 31, 2018 and a prospective phase running from January 1, 2019 to December 31, 2019, a period of 20 years.

\section{5) Sampling}

All cases of benign goiter from 1999 to 2019 have been fully documented.

a) Inclusion Criteria

Included in this study were all patients with histologically confirmed benign goitre, hospitalized and treated in the service.

b) Criteria for Non-Inclusions

Malignant tumour cases were not included in this study.

6) Data Collection Tools:

We have used:

-A survey sheet containing administrative data; clinical data; additional examinations: thyroid assessment; neck radiography; thyroid gland ultrasound; standard preoperative assessment; histology, treatment; post-operative monitoring.

-The consultation logs; the operating logs of the cold room.

7) The Field Phase

The monitoring appointments were carried out in the short, medium and long term: 3 months, 6 months and 1 year. We found information on patients operated by (contacts) for those residing inside the country and home visits for those residing in Bamako.

8) Data Analysis Phase

Word processing and Tables 1-4 were done with Microsoft Word and Excel 2016 software. Data analysis was performed with Epi info 6.fr. The statistical test used was the Khi2 test and a $\mathrm{p}<0.05$ value was considered statistically significant.

\section{Results}

We collected 253 records of benign goitre representing 5.02\% of the 5036 cold block surgical procedures.

The average age of our patients was 42.5 years with a standard deviation of 15.6 and extremes of 13.9 and 76 years.

-Females predominated with a rate of $94 \%$ (238 cases) and a sex ratio of 8.7.

-The average duration of total hospitalization was 3.31, an extreme of 1 to 10 days.

-Antero-cervical swelling was the most common reason for consultation at $90.9 \%$, followed by goiter $9.1 \%$.

Palpitation was the most common sign of hyperthyroidism (17.4\%), followed by insomnia (14.3\%), nervousness (12.2\%) and weight loss (12.2). 
Table 1. Age distribution of patients.

\begin{tabular}{ccc}
\hline Age groups & Workforce & Percentage \% \\
\hline Less than 20 & 7 & 2.8 \\
{$[20-30]$} & 41 & 16.2 \\
{$[31-40]$} & 76 & 30 \\
{$[41-50]$} & 64 & 25.3 \\
{$[51-60]$} & 41 & 16.2 \\
{$[61-70]$} & 21 & 8.3 \\
More than 70 & 3 & 1.2 \\
Total & 253 & 100
\end{tabular}

Table 2. Distribution of patients by sex.

\begin{tabular}{ccc}
\hline Sex & Workforce & Percentage \\
\hline Female & 224 & 88.5 \\
Male & 29 & 11.5 \\
Total & 253 & 100
\end{tabular}

Table 3. Signs of hyperthyroidism according to patients.

\begin{tabular}{ccc}
\hline Signs of hyperthyroidism & Workforce & Percentage \\
\hline Palpitation & $124 / 253$ & 17.4 \\
Insomnia & $102 / 253$ & 14.3 \\
Nervousness & $91 / 253$ & 12.7 \\
Weight loss & $87 / 253$ & 12.2 \\
Anxiety & $63 / 253$ & 8.8 \\
Fine tremor of the extremities & $58 / 253$ & 8.1 \\
Thermophobia & $56 / 253$ & 7.8 \\
Moisture in the hands & $56 / 253$ & 7.8 \\
Diarrhea & $41 / 253$ & 5.4 \\
Hypersudation & $36 / 253$ & 5 \\
\hline
\end{tabular}

Table 4. Distribution of patients by site of swelling.

\begin{tabular}{ccc}
\hline Seat of the tumefction & Effective & Percentage \\
\hline Bilateral isthmolobar & 100 & 39.5 \\
Right isthmolobar & 56 & 22.1 \\
Left isthmolobar & 54 & 21.3 \\
Right lobe & 6 & 2.4 \\
Diffuse & 30 & 11.9 \\
Left lobe & 5 & 2 \\
Isthmus & 2 & 0.8 \\
Total & 253 & 100 \\
\hline
\end{tabular}


-Thirteen percent of patients showed signs of compression with dyspnea, dysphonia and dysphagia were observed in $7.9 \%$ and $6.3 \%$ of patients, respectively.

-Tachycardia was present in $21.3 \%$ of patients.

-The average perimeter of the neck was 43.46 .7 and extremes were $30-62 \mathrm{~cm}$.

-The average diameter of the large axis was $9.33 \mathrm{~cm}$ with a standard deviation of 4.54 and extremes ranging from 2 to $25 \mathrm{~cm}$.

-The mean diameter of the small axis was $6.22 \mathrm{~cm}$ with a standard deviation of 3.24 and extremes ranging from 2 to $20 \mathrm{~cm}$.

-The mean nodule size was 7.9 and extremes were $2-15 \mathrm{~cm}$.

The bilateral isthmolobair goitre was the most common form being $39.5 \%$ followed by the right isthmolobair, left isthmolobair form which represented respectively $22.1 \%$ and $21.3 \%$.

-Eleven percent of patients had a history of family goiter.

-Benign goiter in euthyroid represented $43.5 \%$, benign balanced hyperthyroid goiter represented 52.2\% and Basedow's disease represented $4.3 \%$ in our study.

-postoperative hypocalcemia was observed in $45.5 \%$ of patients.

-Subtotal thyroidectomy was the most performed surgical technique 54.5\%, isth-molobectomy $40.3 \%$, lobectomy $4.4 \%$, and isthmectomy $0.8 \%$. Seventy decimal three percent of patients had micro and macro follicular colloid adenoma, $10.7 \%$ of cases were micro and macro follicular vesicular adenoma, at the end $19 \%$ were micro and macro vesicular hyperplasia.

-Drainage was performed in $88.14 \%$ of patients.

-Four patients had post-operative complications with a type of operatory site infection of $1.6 \%$.

\section{Comments and Discussion}

Endemic goiters are the world's first endemic [5].

-During the study period, 253 patient files were collected. Thyroidectomy represented 5.02\% (253/5036) of surgical procedures; this rate is statistically different from those reported by F. Poumale et al., Koumaré et al. and Ablaye leye et al. [2] [10] [11]. These authors found 3.5\%, 6.2\% and $12 \%$ respectively.

-The average age of our patients was 42.6 years with a standard deviation of 15.62 and extremes of 13.98 and 76 years. This average age is comparable to that of African authors [10] [11].

-The female sex is a risk factor for thyroid pathology, in the study conducted by Touré A et al., they found that the female sex would be a risk factor for the onset of thyroid pathology for hormonal reasons [12].

In our series the female sex was most represented with a ratio sex of 8.7. This result does not differ from that of [13].

The dysthyroidism observed in our series is statistically different from those of Asian, European and African authors [14] [15] [16]. This difference would be explained by recruitment. 
-In our study the signs of cutbacks were $27.2 \%$. These signs are composed of dyspnea $13.0 \%$ (33/253), followed by dysphonia 7.9\% (20/253) at the end dysphagia with a rate of $6.3 \%(16 / 253)$. Yann Sheng Lin and all [16] reported a compression sign rate of $38.6 \%(54 / 140)$. Our result is lower than that of Yann Sheng, this difference is related to the fact that there were cases of goitre diving into his study.

-Exophthalmitis is a major sign of basedow disease. In our study the rate was $4.34 \%$ (11/253) which does not differ from that of Lopez in Mexico [13] but statistically different from those of Aytec in Turkey [14]. This difference would be related to recruitment bias.

-The location of the most common swelling in our series was bilateral isthmolobair localization, 39.5\%, Koumaré and all found $129 / 378$ or (34.1\%) of cases; however in the Colak study. $\mathrm{T}$ et all in Turkey [17], the diffuse form was the most common form at $29 \%$, This deference would be related to recruitment bias.

$11.0 \%(28 / 253)$ in favour of family goiter was noted in our study, Tigabu. E et al. [9] reported in their study that children with a family goiter concept were 2.98 times more likely to develop goiter than children without a family goiter.

The result of our study is different from those of Greisen of Denmark, Kotisso of Ethiopia [18] [19]. This difference could be explained by the lack of knowledge of the family history of some of our patients.

-We noted 41.5\% (105/253) of cooled hyperthyroid goiter and 58.5\% (148/253) of euthyroid goiter, this rate is comparable to those of Koumare et al of Mali which had brought $55.8 \%$ (211/378) cases of euthyroid goiter [2].

In our series, cervical ultrasound was performed in all our patients and has recorded $63.7 \%$ (161/253) of heterogeneous goitre, $21.3 \%$ (54/253) of homogeneous goitre, $13.0 \%(33 / 253)$ of hyperechogenic goitre and $2 \%(5 / 253)$ of isoechogenic goitre. The same ultrasound signs were reported by [20]. The difference observed between our series and those of the others would be related to the anatomy-pathological evolution of the gland.

Cervical radiography was performed in all of our patients and we noted 15.8\% (40/253) of tracheal deviation, 7.5\% (19/253) of calcification and 11.5\% (29/253) of deviation plus tracheal calcification. This rate is comparable to those of Colak in Turkey [20].

-Surgical treatment consisted of subtotal thyroidectomy, right or left isthmolobectomy, lobectomy and isthmectomy depending on the location of the swelling.

We did not perform total thyroidectomy because of the benign goiter of the difficulty in geographic and economic access to thyroid hormone for lifetime hormone therapy.

The same indications have been reported by African authors [2] [11].

In Mali, as in many other African countries it is difficult to give hormonal treatment for life, which is why the subtotal thyroidectomy policy is constant [2].

The histology of all our patients had benign lesions, these same lesions were found by African authors [18] [21]. 
-patients were followed up over a period of one year, followed up with simple procedures in $98.4 \%$ (243/253). We did not experience hemorrhage, recurrent injuries, or recurrence. However, we noted 4 cases of surgical site infection (1.6\%), 2 cases of hypocalcemia ( $0.8 \%)$ and 4 cases of Keloid (1.4\%).

Yann sheng lin and all found $2 / 140$ or $1.4 \%$ cases of hypocalcemia and 2/140 or $1.4 \%$ cases of infection of the operatory site. We have similar results to those of Yann Sheng [2].

\section{Conclusion}

Mali is a country located in the global belt of endemic goiter, which explains the high frequency of goiter in our country. Thyroid surgery is a high-risk surgery that could be improved by early management and quality of intervention. This surgery of benign goiters prevents thyroid cancer. In our department, we have not done a total thyroidectomy for financial reasons because not all patients can provide hormone therapy for life.

\section{Conflicts of Interest}

The authors declare no conflicts of interest regarding the publication of this paper.

\section{References}

[1] Duron, F. and Dubosclard, E. (2000) Goitres Simples: Encyclopedie Médecine Chirurgie. Endocrinologie-Nutrition, Paris, 10-007-A-10.

[2] Koumaré, S., Soumaré, L., Sacko, O., Camara, M., Koïta, A. and Keïta, S. (2016) Prise en charge des goitres en chirurgie A du CHU du point G. Mali Médicale, 31, $1-17$.

[3] Dunn, J.T. and Van der Haar, F. (1992) A Practical Guide to the Correction of Iodine Deficiency. ICCIDD, UNICEF, OMS, 62 p.

[4] Kouamé, P., Koffi, A.O., Nama-Diarra, A.J. and Chaventre, A. (1999) Stratégies de prise en charge d'une endémie goitreuse en situation de développement. Medecine Tropicale, 59, 401-410.

[5] Anderson, M., Takouche, B., Egli, I., Allen, H.E. and De Benoist, B. (2005) Current Global Iodine Status and Progress over the Last Decade towards the Elimination of Iodine Deficiency. Bulletin of the World Health Organization, 83, 518-525.

[6] Sorensen, J.R., Watt, T., Cramon, P., Dossing, H., Hegedus, L., Bonnema, S.J. and Godballe, C. (2017) Quality of Life after Thyroidectomy in Patients with Nontoxic Nodular Goiter: A Prospective Cohort Study. Head \& Neck, 39, 2232-2240. https://doi.org/10.1002/hed.24886

[7] Chalari, D., Gerber, F. and Matter, J. (2017) Le goitre en médicine générale. Forum Médical Suisse, 17, 1095-1102. https://doi.org/10.4414/fms.2017.03134

[8] Fernando, R., Pathmeswaran, A. and Pinto, M.D.P. (2015) Epidemiology of Goiter in Sri Lanka in the Post-Iodization. Ceylon Medical Journal, 60, 41-44. https://doi.org/10.4038/cmj.v60i2.8150

[9] Tigabu, E., Bzkele, B.K. and Dachew, B.A. (2017) Prevalence of Goiter and Associated Factors in Northeast Ethiopia. Epidemiology and Health, 39, e2017055. 
[10] Poumale, F., Doui, A.D., Nghario, L., Issa Mapouka, P.A., Malendoma, J.R., Kossinda, F. and Nali, N.M. (2017) La Chirurgie Thyroïdienne à Bangui: Indications et suites opératoires à Propos de 135 Cas. Human Health and Disease, 18, 39-43.

[11] Lye, Y.M., Diack, N.D., N'dour, M.A., Fall, B., et al. (2016) Les thyroïdectomies au centre hospitalier national de Pikine-Dakar (CHNP): Indications et résultats chez 417 patients. RAFMI, 3, 36-40.

[12] Touré, A., Diallo, A.T., Camara, L.M., Touré, F.B. and Camara, N.D. (2006) La chirurgie thyroïdienne: Expérience du service de chirurgie générale du CHU Ignace DEEN de Conakry. Mali Medical, 21, 23-26.

[13] Lopez, L.H., Herrera, M.F., Gamino, R., Gonzalez, O. and Rivera, R. (1997) Surgical Treatment of Nodular Goiter at the institut national de la nutrition Salvador Zubiran. Revista de Investigación Clínica, 49, 105-109.

[14] Aytac, B. and Karamercan, A. (2005) Recurrent Laryngeal Nerve Injury and Preservation in Thyroidectomy. Saudi Medical Journal, 26, 1746-1749.

[15] Edino, S., Mohammed, A.Z. and Ochicha, O. (2004) Thyroid Gland Diseases in Kano. Nigerian Postgraduate Medical Journal, 11, 103-106.

https://doi.org/10.4314/nqjhm.v11i1.12494

[16] Lin, Y.-S., Wu, H.-Y., Lee, C.-W., et al. (2016) Surgical Management of Substernal Goiters at a Tertiary Referral Center: A Retrospective Cohort Study of 2,104 Patients. International Journal of Surgery, 51, 46-49. https://doi.org/10.1016/j.ijsu.2016.01.032

[17] Pla-Marti, V., Fernandez-Martinez, C., Pallu, Rodriguez-Carrillo, R., Ibanez-Arias, A., Flors-Alandis, C., et al. (2005) Approach to Cytologically-Benign Recurrent Thyroid Cysts. Cirugía Española, 77, 267-270. https://doi.org/10.1016/S0009-739X(05)70852-6

[18] Greisen, O. (2003) A Nodule in the Thyroid Gland. Preoperative Examinations and Treatment-An Analysis of 990 Cases. Ugeskr Læger, 165, 1031-1034.

[19] Kotisso, B., Ersumo, T., Ali, A. and Wassie, A. (2004) Thyroid Disease in Tikuranbessa Hospital: A Five Year Review. Ethiopian Medical Journal, 42, 205-209.

[20] Colak, T., Akca, T., Kanik, A., Yapici, O. and Aydin, S. (2004) Total versus Subtotal Thyroidectomy for the Management of Benign Multinodular Goiter in an Endemic Region. ANZ Journal of Surgery, 74, 974-978. https://doi.org/10.1111/j.1445-1433.2004.03139.x

[21] Lee, J.C. and Siow, J.K. (2002) Thyroid Surgery-The Tan Tock Serg Hospital Otolaryngology Experience. Annals of the Academy of Medicine, Singapore, 31, 158-164. 